\title{
Pemantapan Penggunaan Buku KIA Untuk Pemantauan dan Stimulasi Tumbuh Kembang Anak Selama Pandemi Covid-19
}

\author{
Eliyana Lulianthy ${ }^{I)}$, Indry Harvika ${ }^{2)}$, Gebiyola Palge ${ }^{3)}$, Ika Sri Wahyuni ${ }^{4)}$, Fitri Indriani ${ }^{5)}$, \\ Divia Ichtiarizza Azzahra ${ }^{6}$, Dhita Riyani ${ }^{7)}$, Eva Fajria Ningrum ${ }^{81}$ \\ ${ }^{122(3) 45(567) / 8)}$ Prodi DIII Kebidanan, Politeknik 'Aisyiyah Pontianak, Pontianak, Indonesia \\ Corresponding Author: Eliyana Lulianthy, eliyana.lulianthy@gmail.com
}

\begin{abstract}
Abstrak: Masa Pandemi Covid-19 membuat pelayanan kesehatan pada anak menjadi terbatas. Kegiatan pemantauan dan stimulasi tumbuh kembang yang biasanya dilakukan di Posyandu sementara dihentikan karena adanya pembatasan sosial berskala besar. Oleh karena itu, peran orangtua atau pengasuh sangat besar pada praktik pemantauan dan stimulasi tumbuh kembang pada anak secara mandiri menggunakan Buku KIA. Tujuan kegiatan ini untuk meningkatkan pengetahuan dan sikap orangtua dalam melakukan pemantauan dan stimulasi tumbuh kembang pada anak secara mandiri menggunakan Buku KIA. Kegiatan pengabdian kepada masyarakat dilakukan di wilayah kerja Puskesmas Kampung Dalam Pontianak secara daring manggunakan aplikasi ZOOM meeting. Metode pelaksanaan kegiatan diantaranya ceramah, demonstrasi, pre dan post test. Peserta kegiatan terdiri dari ibu hamil, ibu nifas, dan ibu yang memiliki anak balita usia 0-5 tahun. Hasil analisis statistik deskriptif pada skor rata-rata antara pre dan post test ditemukan peningkatan pada tingkat pengetahuan ibu dari 61,32 menjadi 80,52. Peningkatan juga ditemukan pada skor rata-rata sikap ibu dalam penggunaan buku KIA, yaitu dari 70,52 menjadi 93,68. Kegiatan berjalan lancar walaupun di masa pandemi covid-19. Terdapat peningkatan pengetahuan dan sikap orangtua mengenai pemantauan dan stimulasi tumbuh kembang pada anak secara mandiri menggunakan buku KIA di masa pandemi Covid19.
\end{abstract}

Kata Kunci: Pemantauan \& Stimulasi; Tumbuh Kembang Anak; Buku KIA; Pandemi Covid-19.

\begin{abstract}
During the Covid-19 Pandemic, child health services were constrained. The activities of monitoring and stimulating growth-development that are usually carried out at Posyandu have been temporarily halted due to large-scale social restrictions. Therefore, the role of parents or caregivers is very large in the practice of monitoring and stimulating children's growth-development independently using the Mother Child Health Handbook. Purpose This activity aimed to improve the knowledge and attitudes of parents in independently monitoring and stimulating children's growth-development using the MCH Handbook. Community service activities were conducted in the working area of the Community health center of Kampung Dalam, Pontianak, using the ZOOM meeting application. Methods of activities implementation included lectures, demonstrations, and pre and post tests. Participants in this activity consisted of pregnant women, postpartum mothers, and mothers with children aged 0-5 years. Results Descriptive statistical analysis on the mean value between pre and post test found an increase in the level of maternal knowledge from 61.32 to 80.52. An increase was also found in the average score of mothers' attitudes in using the KIA book from 70.52 to 93.68. Activities ran smoothly despite the large-scale restriction due to Covid-19 Pandemic. The knowledge and attitudes of parents about monitoring and stimulating children's growth-development independently using the KIA book during the Covid-19 pandemic increased.
\end{abstract}

Keywords: Monitoring amd Stimulation; Children's Growth-development; Mother Child Health Handbook; Covid-19 Pandemic.

Submitted: 27.11.2020, Revised: 05.02.2021, Accepted: 06.04.2021 


\section{Pendahuluan}

Masa Pandemi Covid-19 membuat pelayanan kesehatan pada anak menjadi terbatas. Kegiatan pemantauan dan stimulasi tumbuh kembang yang biasanya dilakukan di Posyandu juga ditiadakan karena adanya pembatasan sosial berskala besar (Amalia, Rizki, 2020; Efrizal, 2020). Oleh karena itu, peran orangtua atau pengasuh sangat besar pada praktik pemantauan dan stimulasi tumbuh kembang pada anak. Pemantauan dan stimulasi tumbuh kembang pada anak dapat dilakukan secara mandiri oleh orangtua di rumah menggunakan Buku KIA (Kemenkes RI, 2020). Buku Kesehatan Ibu dan Anak (KIA) merupakan pedoman orangtua dalam melakukan pemantauan dan stimulasi tumbuh kembang. Penggunaan Buku KIA dapat memberikan kontribusi yang baik untuk meningkatkan pengetahuan dan praktik orangtua dalam perawatan anak (Agrina et al., 2016; Aiga et al., 2016; Hikita et al., 2018).

Proporsi kepemilikan Buku KIA di Indonesia Tahun 2018 sebanyak 65,9\% (Riskesdas, 2018). Evaluasi menilai pemanfaatan buku KIA oleh ibu atau pengasuh pada penelitian yang telah saya lakukan mendapatkan hasil bahwa penggunaan Buku KIA belum maksimal. Buku KIA hanya dimanfaatkan sebagai pencatatan imunisasi atau pencatatan berat badan saat posyandu. Alasan informan belum memanfaatkan Buku KIA sangat beragam, yaitu isi Buku KIA standar, belum update dan belum lengkap. Informan lainnya mengatakan bahwa mereka lebih mudah mengakses informasi menggunakan fasilitas internet di handphone.

Buku KIA sebagai panduan bagi orangtua dalam pemantauan dan stimulasi pertumbuhan dan perkembangan pada anak juga dapat memberikan kontribusi yang baik untuk meningkatkan pengetahuan dan praktik orangtua dalam perawatan anak (Aiga et al., 2016). Penelitian dari berbagai bidang ilmu telah menyatakan pentingnya pertumbuhan dan perkembangan anak usia dini pada kesehatan dan produktivitas di seluruh masa kehidupan (Ertem et al., 2018). Anakanak yang memiliki perkembangan sosial dan emosional yang baik akan mendapatkan kepercayaan diri dan kompetensi yang diperlukan dalam membangun hubungan, pemecahan masalah dan mengatasi emosi (Darling-Churchill \& Lippman, 2016).

Kegagalan memberikan nutrisi dan stimulasi yang cukup dalam 1000 hari pertama kehidupan anak akan merusak potensi mereka di masa mendatang (da Cunha et al., 2015). Masa Pandemi Covid-19 ini membuat kagiatan pemantauan dan stimulasi pada tumbuh kembang anak menjadi terbatas. Orangtua, tenaga kesehatan dan kader tidak dapat bertemu karena adanya pembatasan sosial berskala besar. Oleh karena itu, kegiatan pengabdian ini bertujuan untuk meningkatkan pengetahuan dan sikap orangtua dalam melakukan pemantauan dan stimulasi tumbuh kembang pada anak secara mandiri menggunakan Buku KIA. Diharapkan orangtua dapat memanfaatkan Buku KIA dengan baik sebagai sarana pemantauan dan stimulasi tumbuh kembang anak di rumah selama masa pandemi covid-19 ini, sehingga gangguan tumbuh kembang pada anak dapat terdeteksi sejak dini walaupun terbatasnya ruang gerak selama pandemi covid-19. Kebaruan dari kegiatan ini adalah pelaksanaan penyuluhan dan demontrasi kepada masyarakat melalui daring, tidak terbatas ruang dan waktu. Harapannya, orang tua dan masyarakat tetap mendapatkan informasi dan pengetahuan walaupun dengan banyak keterbatasan di masa pandemi Covid-19.

\section{Metodologi}

Kegiatan pengabdian kepada masyarakat ini dilakukan secara daring dari rumah masingmasing menggunakan aplikasi ZOOM meeting, karena adanya pembatasan pertemuan berskala besar di masa pandemi Covid-19. Peserta kegiatan terdiri dari ibu hamil, ibu nifas, dan ibu yang memiliki bayi balita usia 0-5 tahun di wilayah kerja Puskesmas Kampung Dalam. Metode 
dalam pelaksanaan kegiatan pengabdian masyarakat ini diantaranya ceramah, demonstrasi, sharing / tanya jawab dan pre post test.

Peserta mengikuti pemaparan mengenai pemantauan dan stimulasi tumbuh kembang anak secara mandiri di rumah menggunakan Buku KIA. Kegiatan pemaparan ini juga diselingi dengan sesi sharing dengan berbagi pengalaman mengenai pemantauan dan stimulasi tumbuh kembang anak selama masa pandemi covid-19. Sesi terakhir adalah tanya jawab mengenai materi yang disampaikan.

Pada sesi demonstrasi, pengabdi melakukan demonstrasi pemantauan dan stimulasi tumbuh kembang pada anak melalui Buku KIA. Tujuannya agar orangtua atau pengasuh mampu memahami dan mempraktekkan secara mandiri cara pemantauan dan stimulasi tumbuh kembang pada anak menggunakan Buku KIA di rumah.

Pengabdi juga memberikan kuesioner secara daring menggunakan Google Form sebelum dan setelah penyuluhan untuk mengukur tingkat pengetahuan dan sikap ibu dalam melakukan pemantauan dan stimulasi tumbuh kembang anak secara mandiri di rumah selama masa pandemi Covid-19 menggunakan Buku KIA.

\section{Hasil dan Pembahasan}

\section{A. Hasil}

Pandemi Covid-19 ini membuat pertemuan menjadi terbatas, sehingga kegiatan pengabdian masyarakat dilakukan secara daring menggunakan aplikasi Zoom Meeting seperti terlihat pada Gambar 1. Kegiatan ini dilaksanakan pada tanggal 3 Oktober 2020 di Wilayah Kerja Puskesmas Kampung Dalam, Pontianak, Kalimantan Barat. Kegiatan pengabdian kepada masyarakat ini berfokus pada peningkatan derajat kesehatan masyarakat, khususnya kesehatan ibu dan anak. Peserta yang mengikuti kegiatan ini berjumlah 19 orang yang terdiri dari ibu hamil, ibu nifas, dan ibu yang memiliki anak balita usia 0-5 tahun.

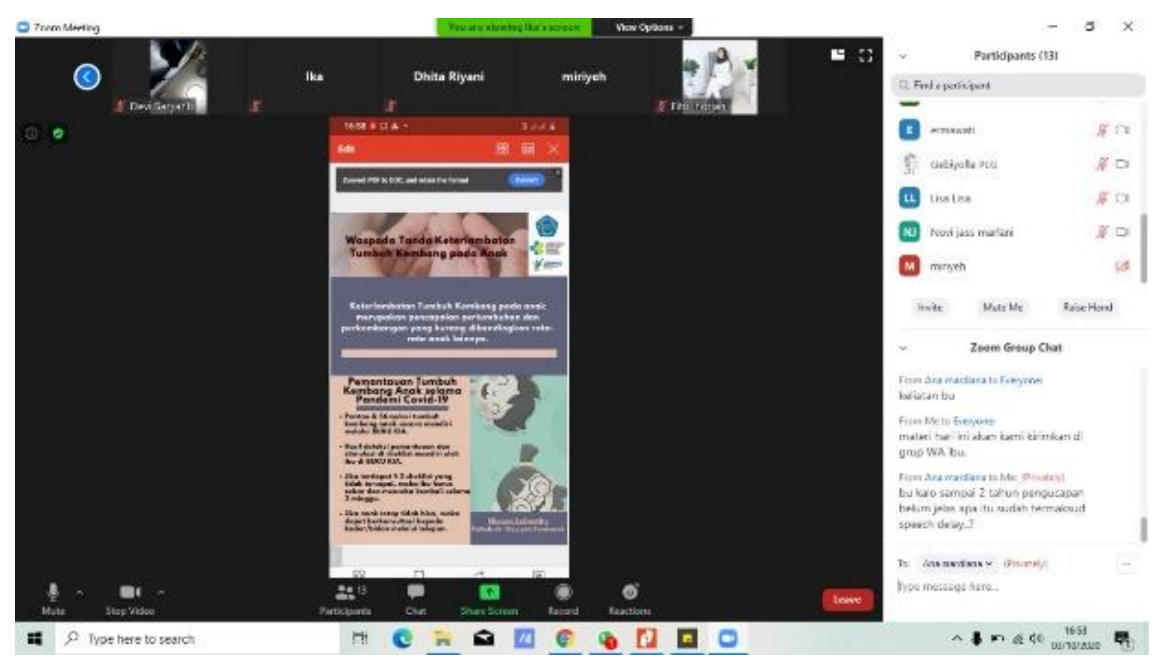

Gambar 1. Kegiatan Pengabdian Masyarakat secara Daring

Pelaksanaan kegiatan diawali dengan memberikan kuesioner pre test kepada sasaran kegiatan, kemudian pemaparan materi mengenai "Pemantauan dan Stimulasi Tumbuh Kembang Anak secara Mandiri di Rumah menggunakan Buku KIA" dan ditutup dengan 
memberikan kuesioner post test mengenai materi yang telah disampaikan. Kegiatan pemaparan materi juga diselingi dengan sesi sharing dan tanya jawab kepada sasaran kegiatan.

\begin{tabular}{ccc} 
Tabel 1. Karakteristik Sasaran Kegiatan & Pengabdian kepada Masyara \\
\hline $\begin{array}{c}\text { Karakteristik Sasaran } \\
\text { Kegiatan }\end{array}$ & Jumlah & $\mathbf{\%}$ \\
\hline Usia Orangtua & & \\
$<20$ tahun & 1 & 5,25 \\
$\mathbf{2 0}-\mathbf{3 5}$ tahun & $\mathbf{1 7}$ & $\mathbf{8 9 , 5}$ \\
$>35$ tahun & 1 & 5,25 \\
Pekerjaan Orangtua & & $\mathbf{1 7 , 5}$ \\
Tidak bekerja & $\mathbf{1 7}$ & $\mathbf{8 9 , 5}$ \\
Bekerja & 2 & 10,5 \\
Usia Anak & $\mathbf{1 1}$ & $\mathbf{5 7 , 9}$ \\
$<\mathbf{1}$ tahun & 8 & 42,1 \\
\hline 1 tahun & 19 & 100 \\
\hline Total Responden & &
\end{tabular}

Tabel 1. pada hasil ini menjelaskan karakteristik sasaran kegiatan pengabdian masyarakat, yaitu usia orangtua, pekerjaan orangtua dan usia anak. Pada karakteristik usia, sebagian besar ibu berusia 20-35 tahun yaitu sebanyak 17 orang (89,5\%). Hasil analisis juga menunjukkan bahwa sebagian besar ibu tidak bekerja yaitu sebanyak 17 orang $(89,5 \%)$. Usia anak dari ibu yang ikut serta pada kegiatan ini sebagaian besar berusia $<1$ tahun yaitu sebanyak 11 orang $(57,9 \%)$.

Tabel 2. Rerata Skor Pengetahuan dan Sikap Ibu

\begin{tabular}{ccc}
\hline & Pre Test & Post Test \\
\hline Pengetahuan & 61,32 & 80,52 \\
Sikap & 70,52 & 93,68 \\
\hline
\end{tabular}

Berdasarkan hasil analisis statistik deskriptif pada rata-rata antara pre dan post test pada tabel 2., ditemukan peningkatan pada tingkat pengetahuan ibu dari 61,32 menjadi 80,52. Peningkatan juga ditemukan pada nilai rata-rata sikap ibu dalam penggunaan buku KIA, yaitu dari 70,52 menjadi 93,68.

\section{B. Pembahasan}

Pengetahuan merupakan segala sesuatu yang diketahui berkenaan dengan sesuatu hal. Pengetahuan atau kognitif merupakan domain yang sangat penting untuk terbentuknya tindakan seseorang (over behaviour). Pengetahuan disebut juga seperangkat ide atau pemikiran yang dimiliki dan digunakan seseorang untuk membuat keputusan yang efektif (Biggs \& Tang, 2011; Serna M. et al., 2017). Berdasarkan hasil analisis statistik deskriptif pada rata-rata antara pre dan post test ditemukan peningkatan pada tingkat pengetahuan ibu.

Peningkatan juga ditemukan pada nilai rata-rata sikap ibu dalam penggunaan buku KIA. Sikap adalah respon tertutup seseorang terhadap stimulus atau objek tertentu, yang sudah melibatkan faktor pendapat dan emosi yang bersangkutan (senang-tidak senang, setuju-tidak setuju, baik-tidak baik, dan sebagainya). Sikap dipersepsikan sebagai alasan tersembunyi dari perilaku seseorang terhadap suatu objek, masalah atau orang lain (Kibrislioglu, 2015; Sayg, 2010). Sikap merupakan faktor penting yang akan mempengaruhi motivasi, minat, dan kinerja seseorang. Berbagai literature mengungkapkan bahwa sikap yang baik memiliki pengetahuan 
yang baik mengenai suatu subjek (Gabel et al., 2019; Hajj et al., 2019; Sharaideh et al., 2013; Suparmi et al., 2015). Teori ini sejalan dengan hasil penelitian kuantitatif yang peneliti dapatkan bahwa responden yang memiliki pengetahuan yang baik memiliki sikap yang baik pula.

Buku KIA merupakan sarana komunikasi, sebagai bentuk media penyuluhan yang memiliki pengaruh besar terhadap pembentukan opini dan kepercayaan seseorang. Buku KIA membawa pula pesan-pesan yang berisi sugesti yang dapat mengarahkan opini seseorang. Adanya informasi baru mengenai sesuatu hal memberikan landasan kognitif baru bagi terbentuknya pengetahuan terhadap hal tersebut. Buku KIA sebagai panduan bagi orangtua dalam pemantauan dan stimulasi pertumbuhan dan perkembangan pada anak juga dapat memberikan kontribusi yang baik untuk meningkatkan pengetahuan dan praktik orangtua dalam perawatan anak (Agrina et al., 2016; Aiga et al., 2016; Hikita et al., 2018; Takeuchi et al., 2016; Yanagisawa et al., 2015).

Kepatuhan dan peran orangtua dalam pemanfaatan Buku KIA dalam pemantauan dan stimulasi tumbuh kembang pada anak memiliki peranan penting untuk keterampilan kognitif, bahasa, dan pribadi-sosial melalui interaksi dengan anggota keluarga (Black \& Surkan, 2015). Berbagai faktor dapat mempengaruhi kepatuhan orangtua dalam menggunakan Buku KIA yaitu faktor predisposisi (usia, jenis kelamin, pendidikan, sikap dan keyakinan, pengetahuan, dan pekerjaan), faktor pendukung (terwujud dalam lingkungan fisik, tersedia atau tidak di sarana dan fasilitas kesehatan) dan faktor pendorong (sikap dan perilaku tenaga kesehatan, peraturan / kebijakan / undang-undang, dukungan keluarga, dan media massa) (da Cunha et al., 2015; Ding et al., 2018; Hofmann et al., 2017; Lisa \& Bruce, 2000; Rushton \& Kraft, 2014; Shin et al., 2013; Takeuchi et al., 2016; Ticusan, 2012; Tocu, 2014).

Tenaga kesehatan berperan penting dalam memberikan informasi mengenai Buku KIA untuk memperkuat pengetahuan dan mengubah sikap dan perilaku dalam memanfaatkan Buku KIA. Komunikasi kesehatan berbasis populasi juga harus ditekankan sesuai dengan kebutuhan masyarakat untuk mendapatkan informasi yang benar dan tepat sebagai sumber informasi untuk meningkatkan kesehatan ibu dan anak.

\section{Simpulan}

Kegiatan pengabdian kepada masyarakat pemantapan penggunaan Buku KIA untuk pemantauan dan stimulasi tumbuh kembang anak selama pandemi Covid-19 telah terlaksana dengan baik. Terdapat peningkatan pengetahuan dan sikap orangtua mengenai pemantauan dan stimulasi tumbuh kembang pada anak secara mandiri di rumah menggunakan buku KIA di masa pandemi Covid-19. Peran tenaga kesehatan sangat besar untuk meningkatkan pengetahuan dan motivasi orangtua untuk dapat melakukan pemantauan dan stimulasi tumbuh kembang anak secara mandiri di rumah, terutama selama pandemi Covid-19. Kegiatan ini diharapkan dapat membantu orangtua untuk deteksi dini adanya gangguan dan keterlambatan tumbuh kembang pada anak.

\section{Ucapan Terima Kasih}

Terimakasih sebesar-besarnya kepada Allah SWT karena memberikan kesehatan dan keselamatan untuk kita semua dalam menghadapi masa Pandemi Covid-19 ini. Terimakasih juga saya sampaikan kepada Politeknik 'Aisyiyah Pontianak karena memberikan dukungan secara moril dan materil sehingga kegiatan ini dapat berlangsung lancar. Ucapan terimakasih juga saya sampaikan kepada Tim Puskesmas Kampung Dalam Pontianak atas kesempatan yang diberikan untuk pelaksanaan kegiatan ini. 


\section{Daftar Pustaka}

Agrina, Suyanto, \& Arneliwati. (2016). the Effect of Reading Maternal and Child Health'S Handbook Campaign At Posyandu (Child Health Post) in Pekanbaru, Indonesia. The Malaysian Journal Of Nursing, 7(2), 27-33.

Aiga, H., Nguyen, V. D., Nguyen, C. D., Nguyen, T. T. T., \& Nguyen, L. T. P. (2016). Knowledge, attitude and practices: Assessing maternal and child health care handbook intervention in Vietnam. BMC Public Health, 16(1), 1-10. https://doi.org/10.1186/s12889-016-2788-4.

Amalia, Rizki, L. U. (2020). View of Penerapan Pengisian Buku KIA Pelayanan Pascasalin dan Menyusui Era Pandemi Covid-19. Jurnal Pengabdian Dan Pemberdayaan Nusantara. http://journal.unublitar.ac.id/jppnu/index.php/jppnu/article/view/20/23.

Biggs, J., \& Tang, C. (2011). Teaching for Quality Learning at University Fourth Edition The Society for Research into Higher Education. www.openup.co.uk.

Black, M. M., \& Surkan, P. J. (2015). Child development and maternal wellbeing: Family perspectives for low-income and middle-income countries. In The Lancet Global Health (Vol. 3, Issue 8, pp. e426-e427). Elsevier Ltd. https://doi.org/10.1016/S2214109X(15)00084-4.

da Cunha, A. J. L. A., Leite, Á. J. M., \& de Almeida, I. S. (2015). Atuação do pediatra nos primeiros mil dias da criança: A busca pela nutrição e desenvolvimento saudáveis. Jornal de Pediatria, 91(6), S44-S51. https://doi.org/10.1016/j.jped.2015.07.002.

Darling-Churchill, K. E., \& Lippman, L. (2016). Early childhood social and emotional development: Advancing the field of measurement. Journal of Applied Developmental Psychology, 45, 1-7. https://doi.org/10.1016/j.appdev.2016.02.002.

Ding, A., Patel, J. P., \& Auyeung, V. (2018). Attitudes and beliefs that affect adherence to provider-based complementary and alternative medicine: A systematic review. In European Journal of Integrative Medicine (Vol. 17, pp. 92-101). Elsevier GmbH. https://doi.org/10.1016/j.eujim.2017.12.002.

Efrizal, W. (2020). Berdampakkah pandemi covid-19 terhadap stunting di bangka belitung? Jurnal Kebijakan Kesehatan Indonesia, 09(03), 154-157. https://journal.ugm.ac.id/jkki/article/view/58695.

Ertem, I. O., Krishnamurthy, V., Mulaudzi, M. C., Sguassero, Y., Balta, H., Gulumser, O., Bilik, B., Srinivasan, R., Johnson, B., Gan, G., Calvocoressi, L., Shabanova, V., \& Forsyth, B. W. C. (2018). Similarities and differences in child development from birth to age 3 years by sex and across four countries: a cross-sectional, observational study. The Lancet Global Health, 6(3), e279-e291. https://doi.org/10.1016/S2214-109X(18)300032.

Gabel, P., Larsen, M. B., Edwards, A., Kirkegaard, P., \& Andersen, B. (2019). Knowledge, attitudes, and worries among different health literacy groups before receiving first invitation to colorectal cancer screening: Cross-sectional study. Preventive Medicine Reports, 14. https://doi.org/10.1016/j.pmedr.2019.100876.

Hajj, A., Hallit, S., Azzo, C., Abdou, F., Akel, M., Sacre, H., Salameh, P., \& Rabbaa Khabbaz, L. (2019). Assessment of knowledge, attitude and practice among community pharmacists towards dental care: A national cross sectional survey. Saudi Pharmaceutical Journal, 27(4), 475-483. https://doi.org/10.1016/j.jsps.2019.01.010.

Hikita, N., Haruna, M., Matsuzaki, M., Shiraishi, M., Takehara, K., Dagvadorj, A., Sumya, N., Bavuusuren, B., Baljinnyam, P., Ota, E., \& Mori, R. (2018). Utilisation of maternal and child health handbook in Mongolia: A cross-sectional study. Health Education Journal, 77(4), 458-469. https://doi.org/10.1177/0017896917753649. 
Hofmann, E., Voracek, M., Bock, C., \& Kirchler, E. (2017). Tax compliance across sociodemographic categories: Meta-analyses of survey studies in 111 countries. Journal of Economic Psychology, 62, 63-71. https://doi.org/10.1016/j.joep.2017.06.005.

Kemenkes RI. (2020). Panduan Kesehatan Balita Pada Masa Pandemi Covid-19. Kementrian Kesehatan RI, 1-60.

Kibrislioglu, N. (2015). An Investigation About 6th Grade Students' Attitudes Towards Mathematics. Procedia - Social and Behavioral Sciences, 186, 64-69. https://doi.org/10.1016/j.sbspro.2015.04.024.

Lisa, B., \& Bruce, T. (2000). Promoting parental compliance with home infant apnea monitor use. Behaviour Research and Therapy, 38(3), 285-296. https://doi.org/https://doi.org/10.1016/S0005-7967(99)00065-0.

Riskesdas, K. (2018). Hasil Utama Riset Kesehata Dasar (RISKESDAS). Journal of Physics A: Mathematical and Theoretical, 44(8), 1-200. https://doi.org/10.1088/17518113/44/8/085201.

Rushton, F. E., \& Kraft, C. (2014). Building brains, forging futures: the pediatrician's role. International Journal of Pediatrics and Adolescent Medicine, 1(1), 3-7. https://doi.org/10.1016/j.ijpam.2014.09.006.

Sayg, C. (2010). Attitude scale development study in relation to music teaching course. Procedia Social and Behavioral Sciences, 2, 5451-5457. https://doi.org/10.1016/j.sbspro.2010.03.889.

Serna M., E., Bachiller S., O., \& Serna A., A. (2017). Knowledge meaning and management in requirements engineering. International Journal of Information Management, 37(3), 155-161. https://doi.org/10.1016/j.ijinfomgt.2017.01.005.

Sharaideh, R., Wazaify, M., \& Albsoul-Younes, A. M. (2013). Knowledge and attitude of school children in Amman/Jordan toward the appropriate use of medicines: A crosssectional study. Saudi Pharmaceutical Journal, 21(1), 25-33. https://doi.org/10.1016/j.jsps.2012.01.001.

Shin, E. S., Hwang, S. Y., Jeong, M. H., \& Lee, E. S. (2013). Relationships of factors affecting self-care compliance in acute coronary syndrome patients following percutaneous coronary intervention. Asian Nursing Research, 7(4), 205-211. https://doi.org/10.1016/j.anr.2013.10.003.

Suparmi, Desanti, O. I., \& Cahyono, B. (2015). The Correlation between Knowledge and Attitude on Food Colorant Uses of PKK Mothers in Penggaron Lor Village. Procedia Food Science, 3, 156-161. https://doi.org/10.1016/j.profoo.2015.01.017.

Takeuchi, J., Sakagami, Y., \& Perez, R. C. (2016). The Mother and Child Health Handbook in Japan as a Health Promotion Tool. Global Pediatric Health, 3, 2333794 X1664988. https://doi.org/10.1177/2333794x16649884.

Ticusan, M. (2012). Training for Being a Parent. Procedia - Social and Behavioral Sciences, 69, 1585-1589. https://doi.org/10.1016/j.sbspro.2012.12.102.

Tocu, R. (2014). Study on the Parental Beliefs and Attitudes towards Child Rearing and Education. Procedia Social and Behavioral Sciences, 137, 153-157. https://doi.org/10.1016/j.sbspro.2014.05.268.

Yanagisawa, S., Soyano, A., Igarashi, H., Ura, M., \& Nakamura, Y. (2015). Effect of a maternal and child health handbook on maternal knowledge and behaviour: A community-based controlled trial in rural Cambodia. Health Policy and Planning, 30(9), 1184-1192. https://doi.org/10.1093/heapol/czu133. 